\title{
Multi-objective Optimization of Turning Performance Characteristics using GA Coupled with AHP based Approach
}

\author{
S. K. Tamang ${ }^{1}$, M. Chandrasekaran ${ }^{1 *}$ \\ ${ }^{1}$ Department of Mechanical Engineering, North Eastern Regional Institute of Science and Technology \\ Nirjuli, Arunachal Pradesh, 791109, INDIA \\ *Corresponding Author
}

DOI: https://doi.org/10.30880/ijie.2021.13.06.012

Received 30 August 2020; Accepted 16 January 2021; Available online 31 August 2021

\begin{abstract}
Heat resistive super alloys (HRSAs) which are commonly known as Inconel alloys are extensively used in aeronautical, food processing and automobile industries. The machinability and parametric optimization of Inconel 825 have not been reported much in the literatures. This study attempts to experimentally investigate and optimize the process parameters during machining Inconel 825 for multiple performance characteristics. Spindle speed $(N)$, feed rate $(f)$ and depth of cut $(d)$ are optimized for different responses namely surface roughness $\left(R_{\mathrm{a}}\right)$, cutting force $\left(F_{\mathrm{z}}\right)$ and metal removal rate $(M R R)$. Feed is found to have the highest influence on $R_{\mathrm{a}}$ and $F_{\mathrm{z}}$. A mathematical model based on multiple regression analysis is developed for predicting $R_{\mathrm{a}}, F_{\mathrm{z}}$ and $M R R$. Taguchi analysis is used for optimizing single objective through mean effect plots. For simultaneously optimizing all the responses a weighted combination of objective function is formulated and optimized using genetic algorithm (GA).The optimum parametric combination being $1200 \mathrm{rpm}, 0.113 \mathrm{~mm} / \mathrm{rev}$ and $0.825 \mathrm{~mm}$ for $N, f$ and $d$ respectively. In the present work analytical hierarchy processes (AHP) is employed for evaluating weights for each performance measures based on their relative importance. Also, Pareto optimality approach is used for obtaining optimum solutions that produce components with maximum $M R R$ at desired value of $R_{\mathrm{a}}$ is another new contribution of this research. The Pareto optimal solution yields a minimum surface roughness of $1.42 \mu \mathrm{m}$ at $N=1204.5 \mathrm{rpm}, f=0.124 \mathrm{~mm} / \mathrm{rev}$ and $d=0.503 \mathrm{~mm}$. This is quite lower than the minimum value of $1.6 \mu \mathrm{m}$ obtained experimentally. The NSGA-II result was verified experimentally and the actual surface roughness obtained was $1.46 \mu \mathrm{m}$ resulting in an error percentage of $2.8 \%$. The developed approach can be economically applied for the production of quality components from Inconel 825 by industries.
\end{abstract}

Keywords: Inconel 825, optimization, taguchi method, GA, AHP, ANOVA

\section{Introduction}

The production of quality products at high production rate are the main challenges for manufacturing industries specially those involved in machining of heat resistive super alloys (HRSAs) used in aerospace and nuclear applications. HRSA such as Inconel 601, Inconel 718, Inconel 750 and Inconel 825are termed as hard-to-machine materials as it possesses high yield strength, high ultimate strength and maintain the ultimate tensile strength even at elevated temperatures. The poor machinability of these materials poses a challenge for manufacturing engineers in selecting appropriate process parameters. The challenges faced are mainly shorter tool life, severe abuse of machined surface and development of higher cutting force [1]. The research studies on turning of Inconel focus mostly on flank wear mechanism and to increase the life of the tool. Hao et al., [2] and Li et al., [3] investigated the flank wear mechanism and obtained optimal cutting temperature during Inconel 718 machining using coated carbide tool. They established a predictive model which gives the optimal cutting temperature and tool flank wear. Jindal et al., [4] studied tool wear of PVD, TiN, TiCN, and TiAlN coated cemented carbide tools in turning of Inconel 718. They found that 
TiAlN and TiCN outperform providing superior tool life as compared to TiN. Rahman et al., [5] carried out machinability analysis on turning Inconel 718 considering three performance measures viz., tool wear, $R_{\mathrm{a}}$ and $F_{\mathrm{z}}$. They found that machinability of Inconel 718 is depends on tool feed rate $(f)$ and cutting speed $(v)$ during machining. Arunachalam et al., [6] investigated on work piece surface roughness produced in machining Inconel 718 and concluded that the use of coated carbide with application of coolant generates compressive residual stress, which helps to reduce surface roughness and improves the machinability. Kamata and Obikawa [7] investigated tool life while machinng Inconel 718 with minimal quantity lubrication (MQL) with coated carbide tools. They found that better tool life achieved by TiCN/Al $\mathrm{O}_{3} / \mathrm{TiN}$ while machining with $1.0 \mathrm{~m} / \mathrm{min}$; it also produce good surface quality.

Thakur et al., [8] performed the machining investigation considering the surface quality of Incoloy 825 during plain turning in dry condition using carbide coated and uncoated cutting tool. They have seen good performance of uncoated carbide insert and produce better surface finish and tool wear. Thakur et al., [9] has established a fuzzy based predictive model for predicting the sub surface micro hardness of Inconel 825 in dry turning using CVD tools. The developed model predicts micro hardness with an average error of 1.07 and $1.18 \%$ respectively for the two different tools. They also studied tool wear and chip characteristics while machining of Inconel 825 using uncoated PVD tool and cemented carbide inserts [10]. The authors noticed that PVD tool show improved tool wear and it is obtained at high cutting speed using coated carbide inserts. Thakur et al., [11] evaluated and compared the frictional \& wear properties and machinability study during turning on Inconel 825 using CVD and PVD tools. The analysis establish that, considerable reduction in main cutting force is shown by PVD coated tool. Santhanakumar et al., [12] studied on work piece surface finish and tool flank wear in turning of nickel based maraging steel. The found that at higher cutting speed and lower feed \& depth of cut surface roughness and tool wear are $0.434 \mu \mathrm{m} 0.0234 \mathrm{~mm}$ respectively. Various studies have been performed by using MQL approach to improve the machinability performance index by number of researchers. Pandey et al., [13] investigated the performance of Trihexyltetradecylphosphonium Chloride mixed with organic coconut oil applied by MQL approach during turning of hardened D2 steel. They found improvement in performance characteristics such as tool wear, surface roughness, material removal rate, and chip morphology. Choudhury et al., [14] studied machinability of 330 Super Alloy using Coconut Oil Based SiO2 Nano fluid in turning. They investigated the effects of input process variables on flank wear, surface roughness, MRR, and chip morphology using MQL technique. The study reported that the machinability has been improved significantly with the use of Nano fluid during the machining process. Kumar et al., [15] have developed spray cooling technique using TiO2 Nano fluid to dissipate the heat from cutting zone during turning which enhanced the life of tool and also give better surface finish. Further they optimize the process parameters such as cutting speed, feed, and depth of cut, air pressure and water pressure using Grey relational analysis and developed a predictive model using artificial neural network (ANN). Comparative study has been performed to instigate the machining performances and wear characteristics of coated carbide and ceramic inserts for AISI D2 steel $(55 \pm 1 \mathrm{HRC})$ during turning. It is found that ceramic insert outperform the carbide in terms of better surface roughness and tool wear [16]. Roy et al., [17] [18] investigated the machining performance viz., tool wear and surface finish during machining of AISI 4340 steel by hard turning process in Pulsating mode using MQL-Assisted lubrication technique. They concluded that the technique reduces tool failure rate as well as shows the improvement in surface finish.

The optimization of machining process is an important task to produce the components economically. For proper optimization, the prediction of various machining performance measures such as surface roughness obtained, tool wear, cutting force, and material removal rate are necessary and it is a challenging task [19]. The conventional modeling and optimization approaches such as (i.e., Taguchi approach, regression model, and response surface methodology) have been used by a number of researchers. Ramanujam et al., [20] have also performed machining investigation of Inconel 718 using PVD coated carbide tool. They established a non-linear relationship model to predict surface roughness and cutting force; found that the deviation in the developed model is very less when it compared to experimental results. Selvakumar and Ravikumar [21] studied the effect of machining parameters ( $v: 2500-3500 \mathrm{rpm} ; f: 4-12 \mathrm{~mm} / \mathrm{rev}$; and $d: 5-15 \mu \mathrm{m}$ ) in turning of titanium alloy using micro tool made up of cermet insert. Cutting speed and feed rate are found as most inducing parameters on flank wear and surface roughness. The developed RSM models show better prediction with residuals lie closer to straight line. Gupta and Sood [22] studied the parametric influences in machining AISI 4340 steel with uncoated tungsten carbide tool. Taguchi based grey relational analysis (GRA) is implemented to optimizing multiple performance measures in different machining environment (dry, wet and cryogenic). The results found that for instantaneously optimize $F_{z}, v b$ and $R_{\mathrm{a}}$, the optimal parameters as cutting speed as $51 \mathrm{~m} / \mathrm{min}$, feed rate $0.179 \mathrm{~mm} / \mathrm{rev}$ machined with cryogenic cooling as optimum parameters. Kacal and Gulesin [23] employed Taguchi approach to optimize the $R_{\mathrm{a}}$ and $F_{\mathrm{z}}$ during turning of austempered ductile iron with CBN tool. Cutting speed, tool type, feed rate and austempering temperature was used as process variables. Feed rate and austempered temperature was found to be significant parameters: Genetic algorithm (GA) is commonly used by researchers for obtaining optimal solution for multiple objectives. Baraskar et al., [24] also used GA to optimize multiple objectives (minimize $R_{\mathrm{a}}$ and maximize $M R R$ ) in EDM. Senthilkumaar et al., [25] also used GA for optimizing finish turning and facing processes of Inconel 718 for minimizing surface roughness and tool wear. Fuzzy and PSO is used for prediction and optimizing the output characteristics. The methodology obtains Pareto's fronts at a reasonably low computational cost, assigning random weights. This again does not guarantee the optimal solution. 
In reviewing the existing literatures, it is very obvious that most literatures focus on the machinability analysis of nickel and titanium-based alloys [26]. The selection of best machining conditions for production of quality components economically is an important area of research. Machining of Inconel 825, which has superior corrosive and oxidization resistance than Inconel 718 has not received much attention. Applications of these materials are found in producing marine, nuclear power, aerospace, chemical, petro-chemical and space shuttle components. The objectives of the present work are drawn as:

1. Experimental study on dry turning of Inconel 825 uisng PCD cutting insert was carried out.

2. The optimizing of process parameters for multiple performance characteristics viz., surface roughness, main cutting force and metal removal rate was studied using GA -AHP.

3. Using the Pareto optimality approach, was used to developed an optimized process parameter table which also provides and facilitate easy selection of process parameters in order to achieve the desired surface roughness and $M R R$.

\section{Materials and Methods}

In the present work, machining of Inconel 825 was conducted on Inconel 825 using poly crystalline diamond (PCD) inserts (Designation of the insert: CNMG 120404-PD 103 (Make: Alumina) having side rake angle of $7^{\circ}$, rake angle of $-6^{\circ}$ clearance angle of $0^{\circ}$, end cutting edge angle of $5^{\circ}$, approach angle of $95^{\circ}$ and nose radius of 0.8 $\mathrm{mm})$. The mechanical property of the Inconel 825 is given in Table 1 .

Table 1 - Mechanical Properties of Inconel 825 (wt\%)

\begin{tabular}{ccccccc}
\hline Material & \multicolumn{2}{c}{ Yield strength } & \multicolumn{2}{c}{ Ultimate tensile strength } & $\begin{array}{c}\text { Elongation percent in } \\
\text { 2" }(50 \mathrm{~mm})\end{array}$ & $\begin{array}{c}\text { Hardness } \\
\text { Rockwell B }\end{array}$ \\
\cline { 2 - 4 } & $\mathrm{psi}$ & $\mathrm{MPa}$ & $\mathrm{psi}$ & $\mathrm{MPa}$ & & 45 \\
\hline Inconel 825 & 49,000 & 338 & 96,000 & 662 & $135-165$ \\
\hline
\end{tabular}

The cylindrical specimen of size $40 \mathrm{~mm}$ diameter and length of $140 \mathrm{~mm}$ was used, poly crystalline diamond inserts tool were used during machining the work material. The experimental work is performed in HMT lathe (Model NH-26) having $11 \mathrm{~kW}$ power. The experimental combinations and number of runs are planned based on central composite design (CCD). The design contains 20 runs of experiment which was performed in dry turning. Based on the preliminary experiments and earlier investigations, three influencing factors $(N, f$ and $d)$ selected and set at three levels as shown in Table 2. Fig 1(a) shows the inputs levels and responses used and Fig. 1 (b) shows machining setup employed.

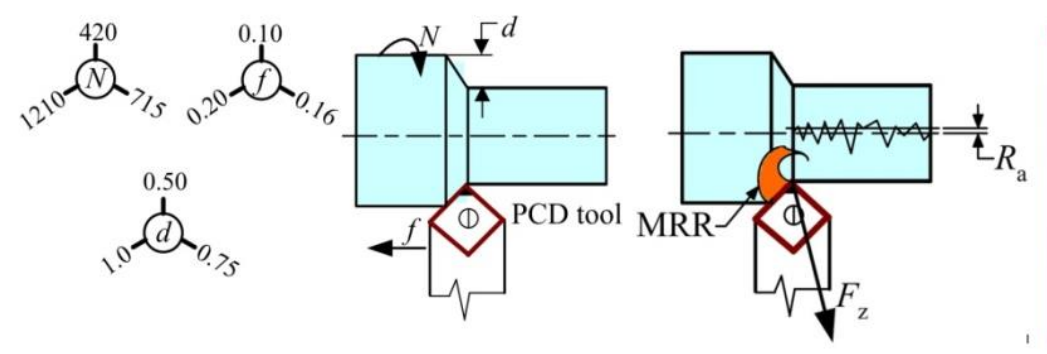

(a) Input levels and response diagram

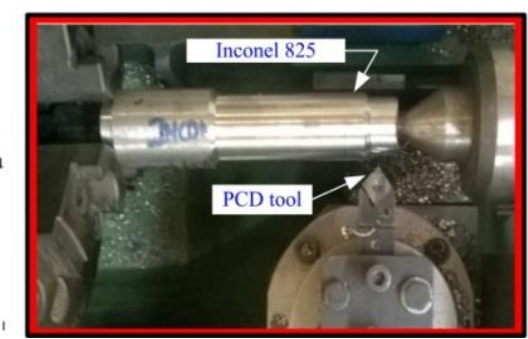

(b) Machining setup

Fig. 1 - Inconel 825 turning process (a) Input levels and response diagram; (b) Machining setup

The machining performance is evaluated with process characteristics i.e., surface roughness $\left(R_{\mathrm{a}}\right)$, main cutting force $\left(F_{z}\right)$ and metal removal rate $(M R R)$. The value of $R_{\mathrm{a}}$ is measured with Pocket Surf (Mahr, GMBH). The measurement of surface roughness was taken with scanning length of $2.4 \mathrm{~mm}$. The measurement was performed at three places such that the entire machining length is divided into three parts and one measurement was taken from each part and average was considered. The obtained $R_{\mathrm{a}}$ measurements are closer and outliers are very small. There is no influence on specific location of job in the measurement of $R_{\mathrm{a}}$. Piezo electric type (Kistler make, type 9272) having threshold measurement of $0.02 \mathrm{~N}$ in z-direction dynamometer was used to measured $F_{\mathrm{z}}$. Once the dynamometer detected cutting signals for the $\mathrm{x}, \mathrm{y}$ and $\mathrm{z}$ axles, the charge amplifier (Kistler make) amplified the signals, which was then transmitted through an interface card into the computer to calculate the three axial cutting forces, $F_{x}, F_{y}$ and $F_{z}$. The $M R R$ is evaluated using an empirical relation given in Eq.1.

$$
M R R=\pi \mathrm{D} N f d,
$$


Where $D$ is diameter of the work piece in mm, $N$ is spindle speed of the machine in rpm, $f$ is feed rate in mm/rev and $d$ is depth of cut in $\mathrm{mm}$. Table 1 shows the designated data sets with actual parameters and the corresponding experimental responses.

Table 2 - Experimental result based CCD experimental design

\begin{tabular}{cllllll}
\hline Trial & \multicolumn{3}{c}{ Actual factors } & & \multicolumn{2}{c}{ Experimental responses } \\
\cline { 2 - 6 } No. & $N(\mathrm{rpm})$ & $f(\mathrm{~mm} / \mathrm{rev})$ & $d(\mathrm{~mm})$ & $R_{\mathrm{a}}(\mu \mathrm{m})$ & $F_{z}(\mathrm{~N})$ & $M R R\left(\mathrm{~mm}^{3} / \mathrm{min}\right)$ \\
\hline 1 & 715 & 0.16 & 0.75 & 2.50 & 382 & 10237.7 \\
2 & 715 & 0.16 & 0.50 & 2.26 & 273 & 6825.1 \\
3 & 420 & 0.16 & 0.75 & 3.51 & 347 & 6013.7 \\
4 & 1210 & 0.16 & 0.75 & 2.03 & 416 & 17325.3 \\
5 & 715 & 0.10 & 0.75 & 2.80 & 280 & 6398.5 \\
6 & 715 & 0.20 & 0.75 & 3.47 & 470 & 12797.1 \\
7 & 715 & 0.16 & 0.75 & 2.50 & 382 & 10237.7 \\
8 & 715 & 0.16 & 0.75 & 2.50 & 382 & 10237.7 \\
9 & 420 & 0.20 & 1.00 & 4.01 & 520 & 10022.9 \\
10 & 420 & 0.20 & 0.50 & 3.57 & 300 & 5011.4 \\
11 & 420 & 0.10 & 0.50 & 2.65 & 148 & 2505.7 \\
12 & 715 & 0.16 & 0.75 & 2.50 & 382 & 10237.7 \\
13 & 1210 & 0.10 & 0.50 & 1.60 & 180 & 7218.9 \\
14 & 1210 & 0.10 & 1.00 & 1.85 & 367 & 14437.7 \\
15 & 715 & 0.16 & 0.75 & 2.50 & 382 & 10237.7 \\
16 & 1210 & 0.20 & 0.50 & 2.19 & 381 & 14437.7 \\
17 & 420 & 0.10 & 1.00 & 2.98 & 308 & 5011.4 \\
18 & 715 & 0.16 & 1.00 & 2.63 & 497 & 13650.2 \\
19 & 1210 & 0.20 & 1.00 & 2.55 & 594 & 28875.4 \\
20 & 715 & 0.16 & 0.75 & 2.50 & 382 & 10237.7 \\
\hline
\end{tabular}

\section{Development of Multiple Regression Model}

A mathematical model based on multiple regression analysis (MRA) has been developed to establish the predictive model equations of three process responses during Inconel 825 machining. The developed quadratic model is in the following form.

$$
y=\beta_{0}+\sum_{i=1}^{k} \beta_{i} x_{i}+\sum_{i=1}^{k} \beta_{i i} x_{i} x_{i}^{2}+\sum_{i} \sum_{j} \beta_{i j} x_{i} x_{j}+\varepsilon,
$$

where $y$ is the performance output terms, $\beta_{0}, \beta_{i}, \beta_{i i}, \beta_{i j}$ is the regression coefficients and $\varepsilon$ is the machining error. Based on the experimental performance outputs the model coefficients are evaluated by using MINITAB $16^{\circledR}$ software. The following are the relations obtained for $R_{\mathrm{a}}, F_{\mathrm{z}}$ and $M R R$.

$$
\begin{gathered}
R_{a}=4.1576-0.00301 N-49.3066 f+7.77 d+0.0000013 N^{2}+195.63 f^{2}-4.831 d^{2} \\
-0.00405 N f+2.206 f d-0.000203 N d R^{2}=0.97 \\
F_{z}=-246.171+0.21138 N+660.306 f+416.285 d-0.0001283 N^{2}+986.115 f^{2}-111.022 d^{2} \\
+0.4180 N f+900.698 f d+0.0187 N d \quad R^{2}=0.99 \\
M R R=10955.9-13.4343 N-72862.2 f-14608 d-0.00000096 N^{2}-7.2796 f^{2}-0.3537 d^{2} \\
+89.4892 N f+97153.5 f d+17.9128 N d, \quad R^{2}=0.99
\end{gathered}
$$

Since coefficients of determination $\left(\mathrm{R}^{2}\right)$ are quite close to 1 that confirms the effectiveness of the developed models. The model equations are validated with 12 unused datasets and the results are validated. The average error percentage is found to be within $10 \%$ and model adequacy is about $90 \%$. Fig. 2 shows the graphical plot of the model performance for different response characteristics (i.e., $R_{\mathrm{a}}, F_{\mathrm{z}}$, and $M R R$ ). This shows that the prediction error is highly accurate of the developed model as the maximum error is within $9.5 \%$. 


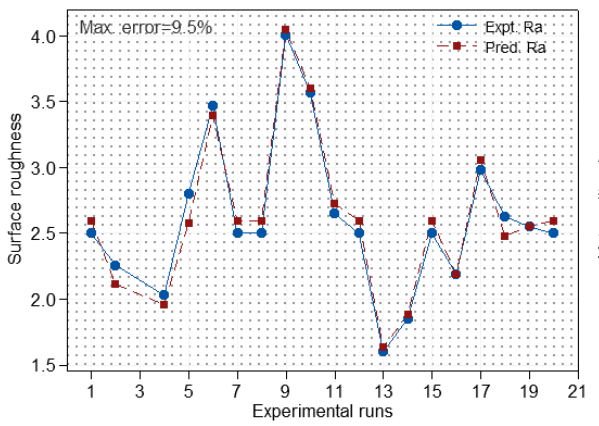

(a) For $R_{\mathrm{a}}$
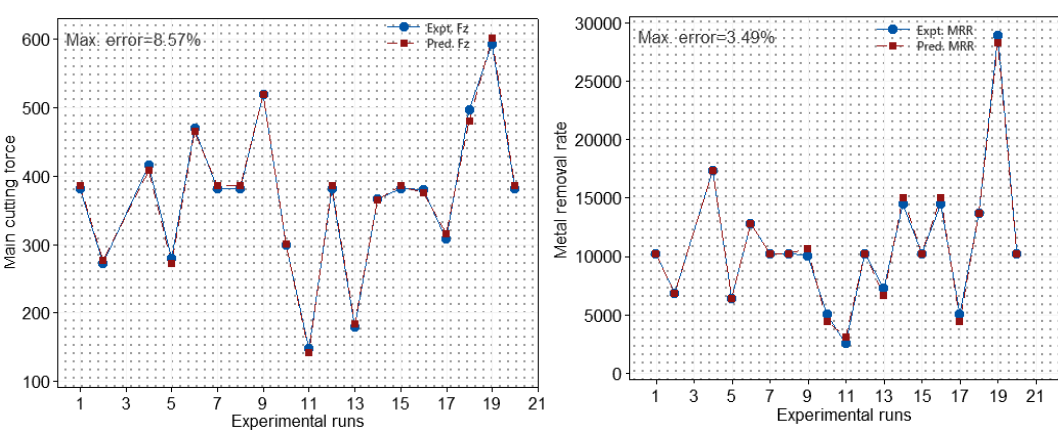

(b) For $F_{z}$

(c) For $M R R$

Fig. 2 - Comparison of model prediction

Fig.3 depicts the interaction effect of influencing factors on different process responses. The graphical analysis of parameters is performed using Design-expert ${ }^{\circledR}$ software, in which, feed and spindle speed are found to be the main dominating parameters. Fig. 3(a) shows the interaction effect of surface roughness $\left(R_{\mathrm{a}}\right)$ and spindle speed $(N)$ with respect to tool feed $(f)$. From the plot, it is evident that with the increase in spindle speed from 420 to $1210 \mathrm{rpm}$, the surface roughness decreases. As the feed rises the $R_{\mathrm{a}}$ is detoriated and produce poor surface finish. The increased feed produces larger waviness on machined surface and hence produces poor surface finish. Fig. 3(b) shows the variation of cutting force with respect to spindle speed and feed. The increase in feed and spindle speed develop higher cutting force. The feed is found to be the main dominating factor and $F_{\mathrm{z}}$ is maximum at $N=750 \mathrm{rpm}$ at all feeds. The higher feed rate is found responsible for increase thickness of chip produced resulting in increase in cutting force. For minimum cutting load lower feed and medium to lower speed is preferred. The variation of metal removal rate (MRR) with respect to $f$ and $N$ is plotted in Fig. 3(c). The plot shows that increase in feed and speed improve MRR. The speed and feed are responsible for increased chip length and chip thickness and hence the increased volume rate of metal removal. For maximum $M R R$, speed and feed are $1210 \mathrm{rpm}$ and $0.2 \mathrm{~mm} / \mathrm{rev}$ respectively.

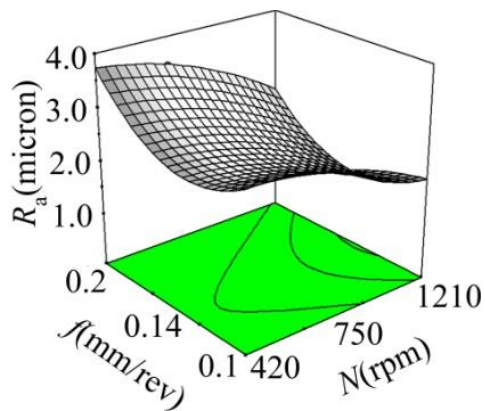

(a) For $R_{\mathrm{a}}$

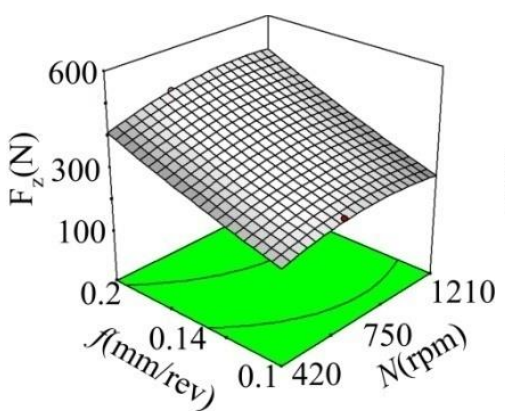

(b) For $F_{z}$

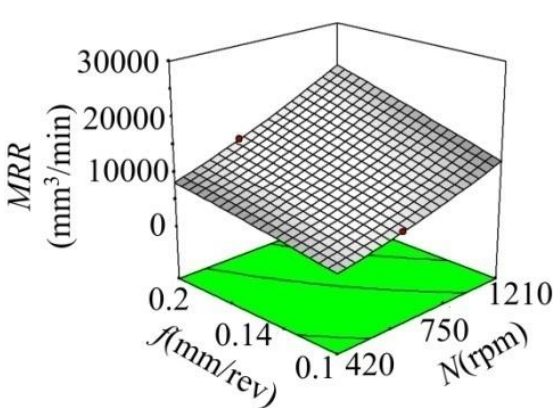

(c) For $M R R$

Fig. 3 - Surface plots (with $f$ and $N$ ) for different performance measures

The investigation shows the effect of various process parameters on different dependent output responses. Analysis has been carried out using design of expert $\left(\mathrm{DoE}^{\circledR}{ }^{\circledR} 11\right)$ software. Table 3 shows ANOVA result for regression model equations (i.e., Eq. 3 to Eq. 5) developed for $R_{\mathrm{a}}, F z$, and $M R R$. The results show $R_{\mathrm{a}}$ is highly influenced by ' $N$ ' contributing $60.69 \%$ and $45.50 \%$ in deciding $M R R$, whereas ' $f$ ' is utmost inducing factor contributing $46.52 \%$ in determining $F_{z}$.

\section{Optimization of Performance Characteristics}

\subsection{Taguchi Optimization of Single Performance Characteristics}

The parametric optimization of machining process is important to produce the component at economic rate. Using Taguchi approach, the quality characteristics of the observed data are represented by the signal to noise $(\mathrm{S} / \mathrm{N})$ ratio $(\eta)$ for normalizing the responses [27]. The characteristic implemented in the present work is represented as:

The smaller the better (SB) S/N ratio (Eqn 6) is used for minimizing surface roughness and cutting force.

$$
\eta_{S B}=-10 \log _{10}\left(\frac{1}{n} \sum_{i=1}^{n} y_{i}^{2}\right),
$$


Where $y_{\mathrm{i}}$ is the observed data at $i^{\text {th }}$ trial and $n$ is the total number of trails. For maximizing material removal rate larger the better (HB) S/N ratio given in Eq.7 is used.

$$
\eta_{H B}=-10 \log _{10}\left(\frac{1}{n} \sum_{i=1}^{n} \frac{1}{y_{i}^{2}}\right),
$$

The higher spindle speed and the low values of feed and depth of cut produce better surface finish. The optimum condition is obtained at $N=1210 \mathrm{rpm}, f=0.1 \mathrm{~mm} / \mathrm{rev}$ and $d=0.5 \mathrm{~mm}$, that producing $R_{\mathrm{a}}$ of $1.60 \mu \mathrm{m}$. The spindle speed is found as an important factor that directly affects $R_{\mathrm{a}}$ as higher speed produces better surface roughness as reported in [28]. The cutting tools with small nose radius/chamfer chip-away the work materials ahead of the tool easily and hence improve the surface roughness. The feed rate and depth of cut are second and least factors respectively that affect the surface roughness inversely. The obtained result agreed with the common finding that speed and feed are the main factors that influence the surface finish.

Table 3 - Analysis of variance for $R_{a}, F_{z}$, and $M R R$

\begin{tabular}{cllllllllllll}
\hline Responses & Source & $\begin{array}{c}\text { Regression } \\
\text { model }\end{array}$ & \multicolumn{1}{c}{$N$} & \multicolumn{1}{c}{$f$} & \multicolumn{1}{c}{$d$} & $N^{2}$ & $f^{2}$ & $d^{2}$ & $N f$ & $f d$ & $N d$ \\
& DF & 9 & 1 & 1 & 1 & 1 & 1 & 1 & 1 & 1 & 1 \\
$R_{a}$ & SS & 6.65 & 4.18 & 1.49 & 0.30 & 0.12 & 0.60 & 0.25 & 0.06 & 0.01 & 0.01 \\
& F-ratio & 32.22 & 182.17 & 65.12 & 12.97 & 4.29 & 26.2 & 10.9 & 2.28 & 0.27 & 0.14 \\
& P-value & 0.00 & 0.00 & 0.00 & 0.005 & 0.05 & 0.00 & 0.00 & 0.046 & 0.042 & 0.03 \\
& Contribution (\%) & 60.69 & 21.68 & 4.32 & 1.43 & 8.72 & 3.63 & 0.76 & 0.081 & 0.05 \\
& DF & 9 & 1 & 1 & 1 & 1 & 1 & 1 & 1 & 1 & 1 \\
$F_{z}$ & SS & 213296 & 9697 & 96951 & 99580 & 950 & 15 & 132 & 557 & 1022 & 28 \\
& F-ratio & 316.81 & 129.62 & 1296 & 1331.1 & 12.7 & 0.20 & 1.77 & 7.44 & 13.66 & 0.37 \\
& P-value & 0.00 & 0.00 & 0.00 & 0.00 & 0.01 & 0.04 & 0.03 & 0.02 & 0.004 & 0.03 \\
& Contribution $(\%)$ & 4.53 & 46.52 & 45.29 & 0.44 & 0.40 & 0.30 & 0.56 & 0.477 & 0.012 \\
& DF & 9 & 1 & 1 & 1 & 1 & 1 & 1 & 1 & 1 & 1 \\
& SS & 613500267 & $2.8 \times \mathrm{e}^{8}$ & $1.33 \times \mathrm{e}^{8}$ & $1.3 \times \mathrm{e}^{8}$ & 0 & 0 & 0 & $2.55 \times \mathrm{e}^{8}$ & $1.18 \times \mathrm{e}^{8}$ & $2.53 \times \mathrm{e}^{8}$ \\
& F-ratio & 245.38 & 1010 & 477.20 & 474.74 & 0 & 0 & 0 & 91.84 & 42.81 & 91.25 \\
& P-value & 0.00 & 0.00 & 0.00 & 0.00 & 1.00 & 1.00 & 1.00 & 0.00 & 0.00 & 0.00 \\
& Contribution $(\%)$ & 45.50 & 21.51 & 21.40 & 0 & 0 & 0 & 4.13 & 1.92 & 4.11 \\
\hline
\end{tabular}

The average S/N ratio for cutting force shows that all the factors directly affect the cutting force; while feed and depth of cut are the most significant factors and speed has the least influence. The optimum parametric combination for minimum $F_{z}$ is $N=420 \mathrm{rpm}, f=0.1 \mathrm{~mm} / \mathrm{rev}$ and $d=0.50 \mathrm{~mm}$ which obtains $F_{z}=148 \mathrm{~N}$. The minimum chip area at lower feed is responsible for producing lower cutting force and thus requires minimum power to shear off the metal. The $M R R$ increases as spindle speed increase; feed rate as well as depth of cut is also responsible for maximum $M R R$. The values of $f$ and $d$ decide the size of the chip while spindle speed is responsible for the volume rate of chip removal from the work piece. The optimal factors for producing $28875.4 \mathrm{~mm}^{3} / \mathrm{min}$ is $N=1210 \mathrm{rpm}, f=0.2 \mathrm{~mm} / \mathrm{rev}$ and $d=1.00 \mathrm{~mm}$. The $\mathrm{S} / \mathrm{N}$ ratio of different responses can be determined using the relation given in the Eq. (8).

$\hat{\eta}_{y}=\eta_{y_{m}}+\left(N_{i}-\eta_{y_{m}}\right)+\left(f_{i}-\eta_{y_{m}}\right)+\left(d_{i}-\eta_{y_{m}}\right)$

where $\eta_{y_{m}}$ is overall experimental mean of corresponding response and $N_{i}, f_{i}, d_{i}(i=1,2$ and 3$)$ are mean response for optimal levels and factors. The comparison of the results between predicted value and the Taguchi optimization of three performance measures i.e., $R_{\mathrm{a}}, F_{\mathrm{z}}$ and $M R R$ are $5.11 \%, 1.69 \%$ and $0.10 \%$ respectively. The predicted values are closer to the experimental value. The estimated $\mathrm{S} / \mathrm{N}$ ratio (maximum) at optimal cutting condition for $R_{\mathrm{a}}, F_{\mathrm{z}}$ and $M R R$ found as $\hat{\eta}_{R_{a}}=-4.08 \mathrm{db}, \hat{\eta}_{F_{z}}=-43.41 \mathrm{db}$ and $\hat{\eta}_{M R R}=89.21 \mathrm{db}$ respectively.

The optimal setting of control factor obtained for single objective case was different for each response (i.e., $R_{\mathrm{a}}$, $F_{\mathrm{z}}$ and $\left.M R R\right)$. Machining of particular combination of optimal factors will not provide optimum result for other response characteristics. Hence for machining quality job economically it is essential for simultaneously optimizing all the responses.

\subsection{Simultaneous optimization using AHP- GA based approach}

The simultaneous optimization of three responses viz., $R_{a}, F_{z}$ and $M R R$ in machining Inconel 825 is performed using a global search non-evolutionary optimization method called genetic algorithm (GA). GA follows the philosophy of natural selection process in evolution to create better and better solutions within a population of random solutions over a number of iterations using its operator i.e., reproduction, crossover and mutation. Initially, a huge set of 
populations are produced within the search boundary. Each solution in the search boundary (i.e., string or chromosome) is given to objective function and the objective value assesses how close the string is near to the desired objective. The method is repetitive till the objective value reaches to the desired precision. The past works confirms that GA is superior optimization method for finding global minima [29].

For simultaneous optimization of all the performance characteristics, a weighting method is used in this study. The outputs of three different objectives (i.e., $R_{\mathrm{a}}, F_{\mathrm{z}}$, and $M R R$ ) provide large differences in numerical values. Therefore, the function corresponding to each machining output is normalized first. The combined weighted objective function employed by Mahapatra and Patnaik [30] is used in this study. The obtained weighted objective function is to be maximized as shown in Eq.9.

$$
\text { Maximize } \mathrm{Z}=\left(w_{1} \times \frac{1}{f_{1}}+w_{2} \times \frac{1}{f_{2}}+w_{3} \times f_{3}\right) \text {, }
$$

Where $f_{1}$ is normalized function for $R_{\mathrm{a}}$,

$f_{2}$ is normalized function for $F_{z}$,

$f_{3}$ is normalized function for $M R R$,

$w_{1}, w_{2}, w_{3}$ are weight function for $R_{\mathrm{a}}, F_{\mathrm{z}}$ and $M R R$ respectively,

The function is optimized subject to following constraints.

$$
\begin{aligned}
& 420 \leq N \leq 1210 \\
& 0.10 \leq f \leq 0.20 \\
& 0.5 \leq d \leq 1.0
\end{aligned}
$$

In multi objective optimization, the problem is optimized considering all objectives simultaneously. Researchers mostly used equal importance (i.e., $\mathrm{w}_{1}=\mathrm{w}_{2}=\mathrm{w}_{3}=0.333$, for optimizing three objectives). However, the importance of objective is not same and it varies from problem to problem. This work proposes an analytical hierarchy process (AHP) for obtaining the weights of different objectives considering their relative importance. AHP was first introduced by Saaty in the year 1990 [31] that uses Eigen vector approach for decision making problems. The information is decomposed into a hierarchy of alternatives and then synthesized to determine relative ranking. This work applies this approach for deriving weights of individual objectives. The priorities based on both qualitative and quantitative information among the objectives $\left(R_{\mathrm{a}}, F_{\mathrm{z}}\right.$ and $\left.M R R\right)$ are evaluated in arriving weightage instead of considering equal weightage in a multi objective optimization problem.

A pairwise comparison matrix considering relative importance of the different objective is obtained initially. The scales of relative importance are as: 1-for equal; 3-for moderate; 5-for strong; 7-for very strong and 9-for extremely strong [24]. For producing quality job economically, $R_{\mathrm{a}}$ and $M R R$ are considered as prime importance. The three different objectives $\left(R_{\mathrm{a}}, F_{z}\right.$ and $\left.M R R\right)$ are related to each other in the following manner:

- $\quad R_{\mathrm{a}}$ is 1.75 times as important as $M R R$

- $\quad R_{\mathrm{a}}$ is 2.5 times as important as $F_{z}$

- $\quad$ MRR is 1.5 times as important as $F_{z}$

Now the pairwise matrix is obtained. The matrix is squared and Eigen vectors are obtained. The Eigen vectors are normalized for obtaining the weights of the iteration. Eq.11 shows the system of weights obtained for optimization.

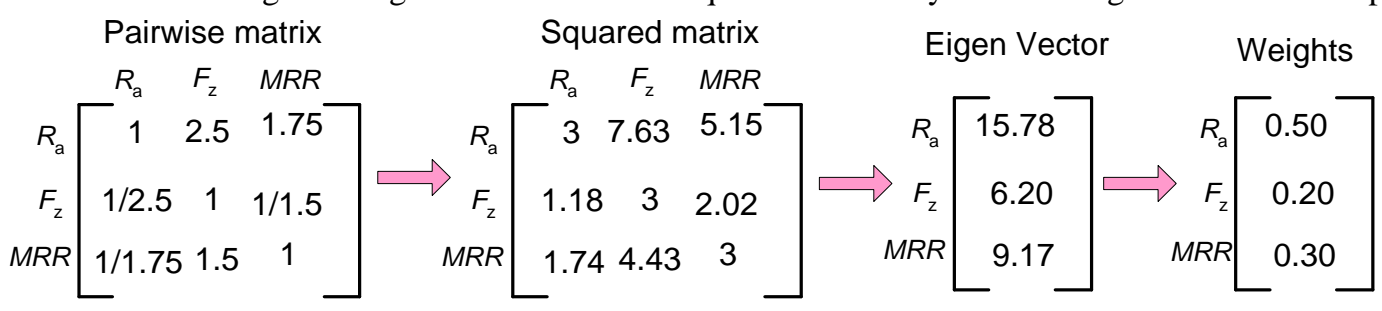

The procedure is repeated till there is no significant variation in the weightage is obtained. The obtained weightages are $0.50,0.2$ and 0.3 for $R_{\mathrm{a}}, F_{z}$ and $M R R$ respectively. The single objective optimization results in diverse best possible solutions. The implementation of one of the optimal condition will provide optimum result for only one response characteristic while other process may deteriorate. For economic benefits of machining process, multiple objective optimization of all the process responses are carried out using GA. The formulated optimization function given in Eq. 8 having weights $w_{1}$ is $0.5, w_{2}$ is 0.3 and $w_{3}$ is 0.2 , is maximized using non-sorting genetic algorithm (NSGA-II) of MATLAB 7.10 ${ }^{\circledR}$. NSGA-II is a multi-objective evolutionary algorithm that uses non-dominated sorting approach, crowded distance estimation procedure, and simple crowded-comparison operator to find a set of evenly distributed solutions to a multi-objective optimization problem. The GA parameters used are: (i) number of population $=20$, (ii) number of iterations $=100$, (iii) cross over probability $=0.95$ and (iv) mutation probability $=0.05$. The optimum parameter was obtained in 135 iterations. The optimum cutting condition is $N=1200 \mathrm{rpm}, f=0.113 \mathrm{~mm} / \mathrm{rev}$ and $d=0.825 \mathrm{~mm}$. The minimum $R_{\mathrm{a}}$ and $F_{z}$ obtained are $2.48 \mu \mathrm{m}$ and $330.38 \mathrm{~N}$. The minimum and maximum experimental 
value of $R_{\mathrm{a}}$ varies between $1.6 \mu \mathrm{m}$ and $3.57 \mu \mathrm{m}$ while $F_{\mathrm{z}}$, between $148 \mathrm{~N}$ and $594 \mathrm{~N}$. The maximum $M R R$ at optimum cutting parameters is $13499.59 \mathrm{~mm}^{3} / \mathrm{min}$ while experimental $M R R$ varies between 2505.7 and $28875.4 \mathrm{~mm} / \mathrm{min}^{3}$ The results show a compromise among the responses based on importance. Table 4 shows the comparison of results of single and multi-objective cases. Taguchi approach is used for optimizing parameters to minimize/maximize the process responses individually. It identifies the best cutting conditions among in different possible levels of combination. The multi objective optimization of process characteristics obtained by GA show a compromise among the responses based on importance.

Table 4 Comparison of results

\begin{tabular}{|c|c|c|c|}
\hline \multirow{4}{*}{ 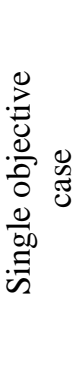 } & Optimum parameters & Function value & $\begin{array}{c}\text { Optimization } \\
\text { approach }\end{array}$ \\
\hline & $\begin{array}{c}N=1210 \mathrm{rpm}, f=0.1 \mathrm{~mm} / \mathrm{rev} ; \\
d=0.5 \mathrm{~mm}\end{array}$ & Min. $R_{\mathrm{a}}=1.6 \mu \mathrm{m}$ & \multirow{3}{*}{ 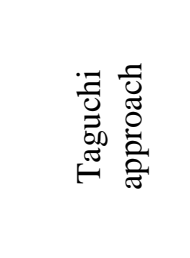 } \\
\hline & & Min. $F_{\mathrm{z}}=148 \mathrm{~N}$ & \\
\hline & $\begin{array}{c}N=1210 \mathrm{rpm}, f=0.2 \mathrm{~mm} / \mathrm{rev} ; \\
d=1.0 \mathrm{~mm}\end{array}$ & $\begin{array}{c}\text { Max. } M R R=28875.4 \\
\mathrm{~mm}^{3} / \mathrm{min}\end{array}$ & \\
\hline 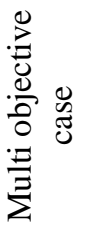 & $\begin{array}{l}N=1200 \mathrm{rpm}, f=0.113 \\
\mathrm{~mm} / \mathrm{rev} ; d=0.825 \mathrm{~mm}\end{array}$ & $\begin{array}{c}\text { Min. } R_{\mathrm{a}}=2.48 \mu \mathrm{m} \\
\text { Min. } F_{\mathrm{n}}=330.38 \mathrm{~N} \\
\text { Max. } M R R=13499.59 \\
\mathrm{~mm}^{3} / \mathrm{min}\end{array}$ & 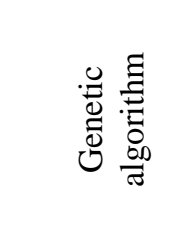 \\
\hline
\end{tabular}

\section{POTENIAL INDUSTRIAL APPLICATION OF PARETO OPTIMALITY APPROACH}

Manufacturing industry mainly aims for producing quality jobs economically and hence the process parameters are optimized for maximizing $M R R$ and minimizing $R_{a}$. It is assumed that the machine could sustain the developed cutting force $\left(F_{\mathrm{z}}\right)$. The multi optimization problem is optimized with NSGA-II using MATLAB $7.10^{\circledR}$ software optimization tool box. Pareto-optimality approach [32] is employed to generate Pareto-optimal fronts for simultaneously optimizing $R_{\mathrm{a}}$ and $M R R$. Pareto optimality is a condition where there is no way to make some response better off without making the other worse off is often referred to as "Pareto optimal" defined by an Italian economist Vilfredo Pareto, who developed the underlying concept. By means of these concepts of optimality multi-objective problems were optimized simultaneously to find out the optimal cutting conditions. It proposes a fitness assignment to each individual in a current population during an evolutionary search based upon the concepts of dominance and non-dominance of Pareto optimality.

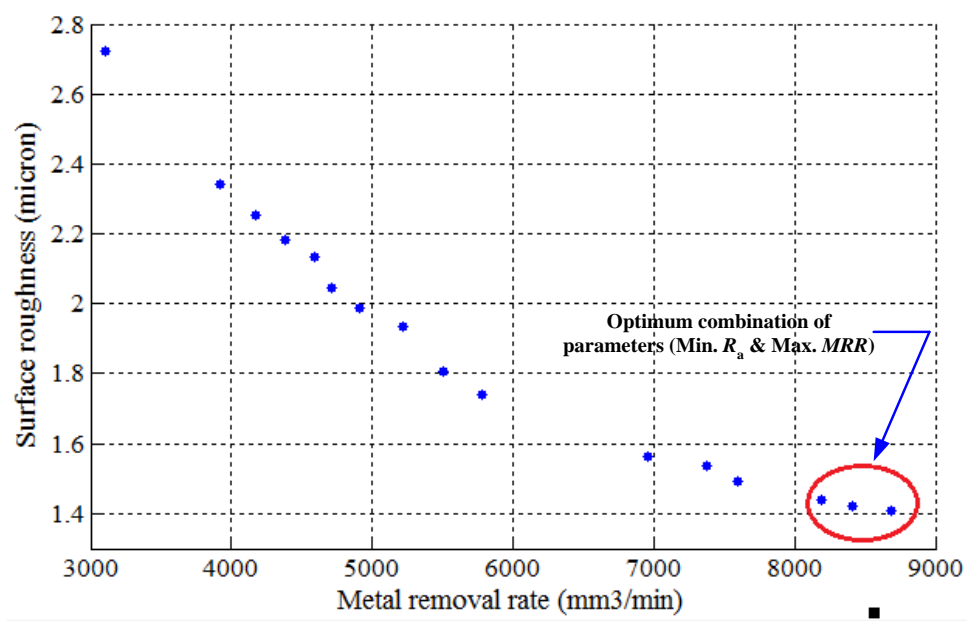

Fig. 4 Pareto optimal solutions

The optimizing functions for surface roughness and $M R R$ are presented in Eq. 3 and Eq. 5 respectively. The lower and upper limits of process parameters define the search boundary for optimization solution. After 161 number of 
iterations, 16 Pareto optimal solutions were generated. Fig.4 shows optimal solutions plotted from GA optimization and the obtained result is presented in Table 5. Referring to Pareto optimal solutions (Table 5), the minimum surface roughness of $1.42 \mu \mathrm{m}$ is obtained at $N=1204.5 \mathrm{rpm}, f=0.124 \mathrm{~mm} / \mathrm{rev}$, and $d=0.503$. It is quite lower than the experimental minimum of $1.6 \mu \mathrm{m}$. The GA result is verified through experimentation and the actual surface roughness obtained is $1.46 \mu \mathrm{m}$, and the error percentage is 2.8 .

Table 5 Optimum process parameter selection for desired responses

\begin{tabular}{cccccc}
\hline Job & \multicolumn{2}{c}{ Optimum parameters } & \multicolumn{2}{c}{ Responses obtained } \\
\cline { 2 - 6 } No. & $N$ & $\begin{array}{c}f \\
(\mathrm{rpm})\end{array}$ & $\begin{array}{c}D \\
(\mathrm{~mm} / \mathrm{rev})\end{array}$ & $\begin{array}{c}M R R \\
(\mathrm{~mm})\end{array}$ & $\begin{array}{c}R_{\mathrm{a}} \\
\left(\mathrm{mm}^{3} / \mathrm{min}\right)\end{array}$ \\
\hline 1 & 1204.94 & 0.124 & 0.503 & 8688.00 & 1.42 \\
2 & 1204.64 & 0.121 & 0.502 & 8407.56 & 1.43 \\
3 & 1203.86 & 0.118 & 0.502 & 8192.64 & 1.45 \\
4 & 1101.25 & 0.118 & 0.502 & 7593.20 & 1.51 \\
5 & 1033.25 & 0.122 & 0.502 & 7372.97 & 1.55 \\
6 & 1046.04 & 0.115 & 0.501 & 6953.14 & 1.57 \\
7 & 989.30 & 0.102 & 0.501 & 5782.51 & 1.75 \\
8 & 950.76 & 0.100 & 0.502 & 5507.20 & 1.82 \\
9 & 752.87 & 0.114 & 0.502 & 5218.23 & 1.94 \\
10 & 756.21 & 0.101 & 0.502 & 4914.13 & 1.20 \\
11 & 726.53 & 0.105 & 0.501 & 4710.88 & 2.05 \\
12 & 630.47 & 0.117 & 0.502 & 4595.87 & 2.14 \\
13 & 618.96 & 0.112 & 0.501 & 4377.35 & 2.19 \\
14 & 603.86 & 0.108 & 0.503 & 4170.20 & 2.26 \\
15 & 571.46 & 0.105 & 0.501 & 3915.90 & 2.35 \\
16 & 420.00 & 0.100 & 0.500 & 3101.01 & 2.73 \\
\hline
\end{tabular}

The ascending order of Pareto solutions based on surface roughness obtained identifies the cutting conditions with minimum $R_{\mathrm{a}}$ and maximum $M R R$. Table 5 may be used by manufacturing industries as a guideline for optimizing Inconel 825 turning process. For instance, if a component to be produced with $R_{\mathrm{a}} \leq 1.60 \mu \mathrm{m}$ (i.e., desired surface roughness $=1.6 \mu \mathrm{m}$ ), table 5 gives appropriate combination of machining conditions providing maximum $M R R$ satisfying surface finish requirement.. Referring to table 4, there are six jobs (job no 1 to 6)/ combinations of cutting conditions that satisfy desired surface roughness. However, the cutting conditions of job no 1 is optimum, which leads to maximum MRR of $8688.0 \mathrm{~mm}^{3} / \mathrm{min}$. The optimal cutting parameters is $N=1204.94 \mathrm{rpm}, f=0.124 \mathrm{~mm} / \mathrm{rev}$, and $d=0.503 \mathrm{~mm}$. The $R_{\mathrm{a}}$ obtained is $1.42 \mu \mathrm{m}$ which is well below the desired surface roughness (i.e., $1.6 \mu \mathrm{m}$ ).Similarly table 5 can be used for obtaining optimum process parameters for different values of $R_{\mathrm{a}}$ ranging from 1.42 to $2.73 \mu \mathrm{m}$. This approach found to be an effective tool for optimizing multiple objectives

\section{CONCLUSIONS}

In this research, experimental study and parametric optimization Inconel 825 turning was performed with simultaneous optimization of surface roughness $\left(R_{\mathrm{a}}\right)$, cutting force $\left(F_{\mathrm{z}}\right)$ and material removal rate $(M R R)$. Taguchi analysis is used for optimizing all the performance measures individually. By simultaneously optimizing all the objectives, a weighted combination of objective function is formulated and then optimized using genetic algorithm (GA). AHP has been used for estimation of weights for each objective, based on their relative importance. The Pareto optimality approach can be easily applied by manufacturing industries for selecting optimal process parameters that would result in producing quality components economically. The same approach could be easily extended for simultaneously optimizing other machining process. The results obtained in this study are summarized below:

1. The experimental investigations show that feed is found to be the highest influencing factor in deciding $R_{\mathrm{a}}$ and $F_{\mathrm{z}}$ while $M R R$ is decided by all the three parameters. Better surface roughness is obtained at high speed and lower tool feed rate.

2. Multiple regression model has been developed for predicting $R_{\mathrm{a}}, F_{\mathrm{z}}$ and $M R R$ exhibiting higher $\mathrm{R}^{2}$ (above 0.90) confirming the suitability of the model. The models were validated with 12 unused datasets and result show model accuracy of $90 \%$ and above.

3. Single objective optimization all performance measures is performed using Taguchi technique through mean effects plots. The predicted results were verified and maximum percentage of error was found to be5.11\%.

4. For simultaneous optimization of $R_{\mathrm{a}}, F_{\mathrm{z}}$ and $M R R$, a weighted combination of objective function was obtained. The weights were optimized through AHP (weights for $R_{\mathrm{a}}, F_{\mathrm{z}}$ and $M R R$ being $0.5,0.3$ and 0.2 ) considering 
relative importance of various objectives. The (NSGA) provides compromised process parameters for all objectives.

5. The Pareto optimal solution yields a minimum surface roughness of $1.42 \mu \mathrm{m}$ at $N=1204.5 \mathrm{rpm}, f=0.124$ $\mathrm{mm} / \mathrm{rev}$ and $d=0.503 \mathrm{~mm}$. This is quite lower than the minimum value of $1.6 \mu \mathrm{m}$ obtained experimentally. The NSGA-II result was verified experimentally and the actual surface roughness obtained was $1.46 \mu \mathrm{m}$ resulting in an error percentage of $2.8 \%$.

6. The optimum process parameter table obtained facilitates machinist in selection of optimum cutting parameters for machining Inconel 825 that would yield values of $R_{\mathrm{a}}$ that ranges from 1.42 to $2.73 \mu$ matmaximum $M R R$. The approach is found to be an effective tool for optimizing multiple characteristics with less effort

Future scope of the present work:

1. The present investigation work can be extended with the inclusion of other characteristics such as tool geometry, acceleration of vibration, machining environment, etc during machining.

2. The work may be extended for evaluation 'tool life' during dry and MQL machining approaches. In addition, the experimental investigation under the cryogenic environment and machinability study and parametric optimization for different performance measures can be investigated.

\section{Acknowledgement}

The authors gratefully acknowledge the experimental facility received from IIT, Guwahati and financial help provided by TEQIP-II (World Bank) of NERIST, Arunachal Pradesh in carrying out the research.

\section{References}

[1] Ezugwu E O, Wang Z M \& Machado A R, The machinability of nickel based alloys: a review. J of Mater Proces Techno, 186 (1999) 1-16.

[2] Hao Z P, Lu Y, Gao D, Fan Y H \& Chang YL, Cutting Parameter Optimization Based on Optimal Cutting Temperature in Machining Inconel 718. Mater and ManufProces, 27 (2012) 1084-1089.

[3] Li L, He N, Wang M \& Wang Z G, High speed cutting of Inconel 718 with coated carbide and ceramic inserts. Mater and ManufProces, 129 (2002) 127-130.

[4] Jindal P C, Santhanam A T, Schleinkofer U \& Shuster A F Performance of PVD TiN, TiCN and TiAlN coated cemented carbide tools in turning. Int J of Refract Metals and Hard Mater, 17 (1999) 63-170.

[5] Rahman M, Seah W K H \&Teo T T, The machinability of Inconel 718. J of Mater ProcesTechnol, 63 (1997) 199204.

[6] Arunachalam R M, Mannan M A \&Spowage A C, Surface integrity when machining age hardened Inconel 718 with coated carbide cutting tools. Int J of Machine Tools and Manuf, 44 (2004) 1481-1491.

[7] Kamata Y \&Obikawa T, High speed MQL finish-turning of Inconel 718 with different coated tools. J of Mater ProcesTechnol,192 (2007) 281-286.

[8] Thakur A, Mohanty A \&Gangopadhyay S, Comparative study of surface integrity aspects of Incoloy 825 during machining with uncoated and CVD multilayer coated inserts. Applied surface science, 320 (2014) 829-837.

[9] Thakur A, Dewangan S, Patnaik Y \&Gangopadhyay S, Prediction of Work Hardening during Machining Inconel 825 using Fuzzy Logic Method. Procedia Material Science, 5 (2014) 2046-2053.

[10] Thakur A, Mohanty A, Gangopadhyay S \&Maity K P, Tool Wear and Chip Characteristics during Dry Turning of Inconel 825. Procedia Material Science, 5 (2014) 2169-2177.

[11]Thakur, A., and Gangopadhyay, S. (2016) Influence of tribological properties on the performance of uncoated, CVD and PVD coated tools in machining of Incoloy 825. Tribiology International, 102, pp.198-212.

[12] Santhanakumar, M., Adalarasan, R., Siddharth, S., Velayudham, A. (2017) An investigation on surface finish and flank wear in hard machining of solution treated and aged $18 \%$ Ni maraging steel. Journal Brazilian Society Mechanical Sciences and Engineering, 39, pp. 2071-2084.

[13]Pandey, A., Kumar, R., Sahoo, A.K., Paul, A., Panda, A. (2020) Performance Analysis of Trihexyltetradecylphosphonium Chloride Ionic Fluid under MQL Condition in Hard Turning. International Journal of Automotive and Mechanical Engineering, 17(1), pp. 7629 - 7647.

[14] Choudhury, A.R., Kumar, R., Sahoo, A.K., Panda, A., Malakar, A. (2020) Machinability Investigation on Novel Incoloy 330 Super Alloy using Coconut Oil Based SiO2 Nano fluid, International Journal of Integrated Engineering, 12 ( 4), pp. 15 - 160.

[15] Kumar, R., Sahoo, A.K., Mishra, P. C., Panda, A., Das, R. K. (2018) Performnace assessment of air-water and TiO2 nanofluid mist spray cooling during turning hardened AISI D2 steel, Indian Journal of Engineering \& Material Sciences, 26, pp. 235 - 253. 
[16] Kumar, R., Sahoo, A.K., Mishra, P. C., Panda, A., Das, R. K. (2018) An investigation to study the wear characteristics and comparative performance of cutting inserts during hard turning. Int. J. Machining and Machinability of Materials, 20(4),pp. 320-344.

[17] Roy, S., Kumar, R., Sahoo, A.K., Paul, A., Panda, A. (2020) Cutting Tool Failure and Surface Finish Analysis in Pulsating MQL-Assisted Hard Turning. J Fail. Anal. and Preven. 20, pp. 1274-1291

[18] Roy, S., Kumar, R., Sahoo, A.K., Paul, A., Panda, A. (2020) Investigation on hard turning temperature under a novel pulsating MQL environment: An experimental and modelling approach. Mechanics \& Industry, 21 (6), 605.

[19] Chandrasekaran M, Muralidhar M, Murali Krishna C \& Dixit U S, Application of soft computing techniques in machining performance prediction and optimization: a literature review. Int J Adv. Manuf. Techno, 46 (2010) 445 $-464$.

[20] Ramanujam R, Venkatesan K, Saxena V \& Joseph P, Modeling and Optimization of Cutting Parameters in Dry Turning of Inconel 718 using Coated Carbide Inserts. Procedia Material Science,5 (2014) 2550 - 2559.

[21] Selvakumar S \&Ravikumar R, Experiential analysis and mathematical modeling of optimized cutting parameters in micro turning. Indian J of Eng Mater Sci, 21(2014) 397- 408.

[22] Gupta M K \&Sood P K, Optimization of Machining Parameters for turning AISI 4340 steel using Taguchi based Grey relational analysis. Indian J of Eng Mater Sci, 22(2015) 679-685.

[23] Kacal A, Gulesin M, Determination of Optimal Cutting conditions in finish turning of austempered ductile Iron using Taguchi design method. J SCI IND RES, 70 (2011) 278 - 283.

[24] Baraskar S S, Banwait S S\&Laroiya S C, Multi objective optimization of electric discharge machining process using a hybrid method. Mater and ManufProces ,28(2013) 348-354.

[25] Senthilkumaar J S, Selvarani P \&Arunachalam R M, Intelligent optimization and selection of machining parameters in finish turning and facing of Inconel 718. Int J AdvManuf Technol,58 (2012) 885 - 894.

[26] Aliakbari E \&Baseri H, Optimization of machining parameters in rotary EDM process by using the Taguchi method. Int J Adv. Manuf. Technol, 62 (2012) 1041-1053.

[27] Taguchi G, Introduction to quality engineering. Tokyo Asian Productivity Organization, Tokyo(1990).

[28] Pawade R S, Suhas S J, Brahmankar P K, \& Rahman M, An investigation of cutting forces and surface damage in high-speed turning of Inconel 718. J Mater Process Technol, (2007) 192-193,139-146.

[29] Kuriakose S \&Shunmugam M S, Multi-objective optimization of wire-electro discharge machining process by Non-Dominated sorting genetic algorithm. Int. J. of Eng\& Mater. Sci, 170 (2005) 133-141.

[30] Mahapatra S S\& Patnaik A, Optimization of wire electrical discharge machining (WEDM) process parameters using Taguchi method. Int. J. Adv. Manuf. Technol,34 (2006): 911-925.

[31] Saaty T L, The Analytic Hierarchy Process. McGraw-Hill International publication, New York(1980).

[32] Deb K, Optimization for engineering design- Algorithms and examples. Prentice-Hall of India, New Delhi(2005). 